\title{
Astrocytes and Aging
}

\author{
Alexandra L. Palmer ${ }^{1}$ and Shalina S. Ousman ${ }^{1,2 *}$ \\ ${ }^{1}$ Department of Neuroscience, Hotchkiss Brain Institute, University of Calgary, Calgary, AB, Canada, ${ }^{2}$ Departments of Clinical \\ Neurosciences and Cell Biology \& Anatomy, Hotchkiss Brain Institute, University of Calgary, Calgary, AB, Canada
}

By 2050 , the aging population is predicted to expand by over $100 \%$. Considering this rapid growth, and the additional strain it will place on healthcare resources because of age-related impairments, it is vital that researchers gain a deeper understanding of the cellular interactions that occur with normal aging. A variety of mammalian cell types have been shown to become compromised with age, each with a unique potential to contribute to disease formation in the aging body. Astrocytes represent the largest group of glial cells and are responsible for a variety of essential functions in the healthy central nervous system (CNS). Like other cell types, aging can cause a loss of normal function in astrocytes which reduces their ability to properly maintain a healthy CNS environment, negatively alters their interactions with neighboring cells, and contribute to the heightened inflammatory state characteristic of aging. The goal of this review article is to consolidate the knowledge and research to date regarding the role of astrocytes in aging. In specific, this review article will focus on the morphology and molecular profile of aged astrocytes, the consequence of astrocyte dysfunction on homeostatic functions during aging, and the role of astrocytes in age-related neurodegenerative diseases.

Keywords: astrocytes, aging, inflammation, neurodegeneration, CNS, microglia, neurons, oligodendrocytes

\section{OPEN ACCESS}

Edited by:

Merce Pallas,

University of Barcelona, Spain

Reviewed by: Christiane Charriaut-Marlangue, Institut National de la Santé et de la Recherche Médicale (INSERM),

France

Dario Acuña-Castroviejo, Universidad de Granada, Spain

${ }^{*}$ Correspondence:

Shalina S. Ousman sousman@ucalgary.ca

Received: 13 August 2018 Accepted: 05 October 2018 Published: 26 October 2018

Citation:

Palmer AL and Ousman SS (2018) Astrocytes and Aging. Front. Aging Neurosci. 10:337. doi: 10.3389/fnagi.2018.00337

\section{INTRODUCTION}

Aging is yet to be pinpointed to one specific factor or cell, but the current consensus is that aging is a multitude of factors (genetic, biological, environmental) that interplay together amongst the various cell types to contribute to physiological and cognitive changes characteristic of the aging process. Aging of the human brain is mainly observed as structural and physiological alterations that are most notably accompanied by cognitive decline. In terms of structure, imaging studies have shown that the aged brain displays a loss of dendritic spines (Pannese, 2011), decreases in oligodendrocyte (OL) number (Pelvig et al., 2008; Fabricius et al., 2013), stem cell loss in the hypothalamus (Zhang et al., 2017), and decreased brain volume across multiple neural regions (Ge et al., 2002; Resnick et al., 2003; Scahill et al., 2003; Raz et al., 2005; Freeman et al., 2008; Driscoll et al., 2009; Fjell et al., 2009; Li et al., 2013; Mu et al., 2017). The decrease in brain volume has been found to vary by sex, with males having more brain atrophy than females (Xu et al., 2000). Further, the reduced brain volume was hypothesized to be due to a loss of neurons (Brody, 1955; Coleman and Flood, 1987; Sturrock, 1989). However, a number of studies have shown that neuronal count does not change with age (Cragg, 1975; Terry et al., 1987; Freeman et al., 2008) and as such, the search for what was responsible (e.g., glia) for the structural changes became an active area of research.

With respect to physiological changes that occur with aging in the central nervous system (CNS), researchers observed an overall increase in gene expression in the brain (Berchtold et al., 2008; Boisvert et al., 2018). Although these genetic changes varied across brain regions and were sex dependent, with males showing more gene changes than females 
(Berchtold et al., 2008), there were some consistent changes. For example, across all brain regions, microglia and endothelial cells increased their gene expression levels, whereas astrocytes and OLs, but not neurons, shifted their expression pattern (Boisvert et al., 2018). Of note, these changes in gene expression in microglia, endothelial cells and astrocytes were of an inflammatory profile, which was intriguing given the well-known development of a mild inflammatory state with age (Howcroft et al., 2013; Morrisette-Thomas et al., 2014; Rea et al., 2018). Further, because the shift in gene expression pattern occurred in glial cells but not neurons, it implied that neurons are not a good indicator of age; instead, it has been proposed that glial specific genes may be a better predictor of age (Soreq et al., 2017). This review article will focus on what is known thus far about changes that occur to astrocytes during aging, the consequence of astrocyte dysfunction during aging on other resident CNS cells, and the role of astrocytes in age-related neurodegenerative diseases.

\section{ASTROCYTES}

Astrocytes were first observed in the brain by Camillo Golgi in 1871. They are the largest cell population in the CNS with a ratio of astrocytes to neurons in the human cortex averaging 1.4:1 (Nedergaard et al., 2003). Astrocytes also represent the most heterogeneous group of glial cells and tile the entire CNS in a non-overlapping manner (Sofroniew and Vinters, 2010). Once considered to be no more than "brain glue" that provides structural support through extracellular matrix formation, astrocytes have now become known for key roles in a variety of complex and essential functions. A few of these functions include synapse development, neurotransmitter homeostasis, glycogen storage and blood brain barrier (BBB) maintenance (Sofroniew and Vinters, 2010). Due to their multifaceted roles, it is not surprising that astrocytes are involved in aging.

\section{Phenotype and Molecular Profile of Aged Astrocytes}

Astrocytes represent the most heterogeneous group of glial cells in terms of molecular, structural and physiological profiles and their classification relies on both morphological and molecular criteria. These glia are morphologically diverse, but are typically stellate-shaped cells with radial processes (Oberheim et al., 2009). With age in humans, there is an alteration in astrocyte phenotype from long and slender processes in young subjects to short and stubby processes in older individuals (Kanaan et al., 2010; Cerbai et al., 2012; Jyothi et al., 2015). This age-related morphological change has also been shown to occur in aged rodents (Castiglioni et al., 1991; Amenta et al., 1998) and primates (Kanaan et al., 2010; Robillard et al., 2016). With respect to numbers, there appears to be region-dependent differences in their density where reductions were noted in the retina of aged rodents (Mansour et al., 2008), while no changes were observed in the hippocampus (Lindsey et al., 1979; Jinno, 2011), and an increase seen in the human cortex (Hansen et al., 1987) and hypothalamus (Wang et al., 2006).
With respect to molecular criteria, glial fibrillary acidic protein (GFAP) has been used as a classical marker for astrocyte identification; although it is important to note that GFAP is not detectable in all astrocytes (Sofroniew and Vinters, 2010). Reports on aging astrocytes have shown that GFAP expression increases (Nichols et al., 1993; Kohama et al., 1995; Yoshida et al., 1996; Rozovsky et al., 1998; Wu et al., 2005; Clarke et al., 2018) and since an increase in GFAP expression is a common feature of reactive/activated astrocytes (Zamanian et al., 2012; Sofroniew, 2014; Liddelow et al., 2017), these findings suggest that astrocytes become reactive with age. More evidence in support of this notion was provided when it was found that astrocyte reactivity involves the differential expression of over 1,000 genes, some of which have been collectively attributed to "A1" reactive astrocytes-astrocytes of a more inflammatory state (Zamanian et al., 2012). Some of these "A1" reactive genes (Zamanian et al., 2012), such as complement system factors, antigen presentation molecules, secretory factors, peptidase inhibition and cholesterol synthesis, were recently identified as additional molecular profiles of aged astrocytes (Boisvert et al., 2018; Clarke et al., 2018). In addition, there is evidence that aged astrocytes undergo epigenetic changes and may alter BBB function and circadian rhythm.

\section{Aging Astrocytes and the Complement System}

The complement system is part of the innate immune system, and aids in regulating inflammation as well as resistance to infection (Markiewski and Lambris, 2007). The system consists of approximately 30 soluble factors that are widely expressed in neurons and glia in the postnatal brain (Stevens et al., 2007; Hammad et al., 2018). C1q and C3 are major complement proteins that allow for cells to be tagged and targeted for phagocytosis (Stevens et al., 2007). During development, postnatal neurons express $\mathrm{C} 1 \mathrm{q}$ at synapses which appears to target unwanted synapses for elimination (Stevens et al., 2007). In the mature brain, the complement system is dampened, however studies have shown that during CNS disease the system becomes enhanced by various cells, including astrocytes, and can lead to pathology via synapse, dendritic spine and neuronal loss, as well as changes in neuronal morphology (Stevens et al., 2007; Stephan et al., 2012; Zamanian et al., 2012; Lian et al., 2015, 2016). An increase in the genes belonging to components $\mathrm{C} 3$ and $\mathrm{C} 4 \mathrm{~B}$ is seen in astrocytes during aging (Boisvert et al., 2018; Clarke et al., 2018). C4B is a protein involved in both the classical and lectin pathway of the complement system. It is also a substrate that allows $\mathrm{C} 3$ convertase to cleave $\mathrm{C} 3$ into $\mathrm{C} 3 \mathrm{a}$ and $\mathrm{C} 3 \mathrm{~b}$, which direct both of these pathways toward opsonization and cell lysis. C3 is required for both these pathways, however it can also function on its own through the alternative pathway where it is involved in inflammation, cell migration, activation and cell lysis. This suggests that astrocytes are able to functionally partake in all three pathways of the complement system.

The activation of complement by aged astrocytes may contribute to cognitive decline. More specifically, because overall neuronal loss was not seen in aging humans, it has been suggested that changes in neuronal structure may instead be the culprit 
responsible for age-associated cognitive impairment (Berchtold et al., 2008). Since the current consensus is that memories are formed when neurons fire to one another, and recollection of that memory strengthens the associated synapses (Mayford et al., 2012), it is feasible that loss of a strengthened connection (synapse) between two neurons via complement targeting by reactive aged astrocytes could contribute to the memory deficits characteristic of elderly people (Choi et al., 2018).

\section{Antigen Presentation and Aging Astrocytes}

The aging astrocyte also shows an upregulation in genes comprising major histocompatibility complex I (MHC I; Orre et al., 2014; Boisvert et al., 2018; Clarke et al., 2018), which is in agreement with other literature showing that there is an overall age-related increase in brain MHC I (Mangold et al., 2017). Interestingly, $\mathrm{H} 2-\mathrm{K} 1$ and $\mathrm{H} 2-\mathrm{D} 1$, both of which are upregulated in aging astrocytes and form part of MHC I, are associated with increased expression of pro-inflammatory genes (Mangold et al., 2017), implying that astrocytes could contribute to the low level inflammatory state that is characteristic of aging. That is, although contentious as to whether astrocytes present antigens in vivo, an increase in MHC I in astrocytes would suggest that these glia have an increased propensity to present antigens. More specifically, even though these glia are not professional antigen presenting cells (APCs) by definition, and they present antigens weaker than professional APCs, if only a subset of astrocytes presented antigens, the amount of overall antigen presentation would be large based on the sheer number of this glial cell in the CNS. Further support for the antigen presenting ability of aged astrocytes in vivo is their significant expression of various factors involved in phagocytic pathways, including Pros1, Mfge8, Megf10, Lrp1 (Clarke et al., 2018); Mertk expression was not significantly increased, but was still expressed by aged astrocytes (Clarke et al., 2018). These results suggest that astrocytes possess the tools needed to tag (Mfge8, Pros 1, C3b), phagocytose (Mertk, MegF10, Lrp1) and present (H2-K1, H2-D1) antigens. However, Megf10, Mertk and Lrp1 expression does not necessarily signify negative consequences such as inflammation, because astrocytes may utilize these receptors for debris clearance. That is, astrocytes were found to possess lipid inclusions which contained myelin in the aging human optic nerve suggesting that astrocytes may be trying to clear myelin debris during aging (Nag and Wadhwa, 2012). Furthermore, apart from its immunological role, MHC I has been shown to be increased significantly with age in cognitively-intact individuals, but decreased in cognitively impaired individuals (Lazarczyk et al., 2016). This suggests that MHC I expression may have a positive role in brain aging by trying to preserve cognitive function. Thus, the antigen presentation capability of astrocytes with age may be both advantageous and detrimental depending upon the context. Further work needs to be done to elucidate exactly how these phagocytic factors in aged astrocytes are contributing to aging and whether they are detrimental, protective, or both.

\section{Aged Astrocytes and Secretory Molecules}

Another characteristic feature of aged astrocytes is an increase in production of cytokines such as CXCL10/inducible protein-10
(IP-10; Clarke et al., 2018). CXCL10 serves as a chemoattractant for peripheral immune cells, and aids in $\mathrm{T}$ cell adhesion to endothelial cells (Sorensen et al., 2018). Interestingly, the receptor for CXCL10 is CXCR3, a microglia marker, suggesting that astrocytes and microglia may be communicating with each other during aging. This is entirely plausible as recent literature shows that microglia are able to induce reactivity in astrocytes (Liddelow et al., 2017; Rothhammer et al., 2018).

CXCL5 is another cytokine whose expression is augmented in aged cerebellar astrocytes (Boisvert et al., 2018). Like CXCL10, CXCL5 has chemotactic capabilities and has been shown to be involved in neutrophil recruitment ${ }^{1}$, and like astrocytes, neutrophils display aging deficits including an increase in their inflammatory properties (Adrover et al., 2016). Astrocytes have been shown to have both a direct (cell to cell) and indirect effect on polymorphonuclear neutrophils (Xie et al., 2010). That is, astrocytes are able to attenuate pro-inflammatory cytokine expression in neutrophils through direct contact, while an indirect interaction has been attributed to enhanced neutrophil necrosis (Xie et al., 2010). Therefore, it is plausible that aged astrocytes and aged neutrophils could synergistically elicit a heightened inflammatory response.

In addition to chemotactic and survival effects on immune cells via cytokine release, aged cortical astrocytes may negatively impact CNS health because of a decline in production of certain metabolic and trophic factors such as ATP and neurotrophins. For instance, a decline in ATP release may contribute to cognitive decline and impaired synaptic plasticity because ATP is involved in regulating neuronal activity through synaptic and tonic inhibition (Lalo et al., 2014). In addition, neuronal survival and neurogenesis may be decreased due to a reduction in the secretion of neurotrophins like vascular endothelial growth factor (VEGF), fibroblast growth factor 2 (FGF2; Bernal and Peterson, 2011) and brain derived neurotrophic factor (BDNF) in aged astrocytes (Bellaver et al., 2017).

\section{Oxidative Stress and Aging Astrocytes}

Oxidative stress is a key component to aging and age-related diseases, including neurodegenerative diseases. The accumulation of oxidative damage, specifically to lipids, DNA, and proteins (Dizdaroglu et al., 2002; Cooke et al., 2003; Evans et al., 2004; Swain and Subba Rao, 2011), is proposed to result in age-associated functional losses in a process referred to as the free radical theory of aging or oxidative stress theory of aging (Beckman and Ames, 1998; Liguori et al., 2018). Indeed, increased reactive oxygen species (ROS) which cause damage to lipids, proteins, and DNA is frequently observed in aged tissue (Kudin et al., 2008; Brawek et al., 2010; Lukiw et al., 2012).

Middle-aged astrocytes have been shown to accumulate ROS and display an overload in $\mathrm{Ca}^{2+}$ (Ishii et al., 2017). Moreover, the over-abundance of $\mathrm{Ca}^{2+}$ was associated with an increase in JNK/SAPK activation, which is a member of the stress-activated MAPK signaling pathway, and which has been linked to cell death signaling (Ishii et al., 2017). Of further note, astrocytes

\footnotetext{
$\overline{{ }^{1} \text { https://www.ncbi.nlm.nih.gov/gene/6374 }}$
} 
that have been exposed to oxidative stress factors during aging begin to undergo oxidative stress themselves (Lei et al., 2008; Lu et al., 2008; Bellaver et al., 2017), and in age-associated neurodegenerative diseases such as multiple sclerosis (MS), astrocytes in active lesions have been shown to increase their accumulation of oxidized lipids and proteins in their cytoplasm (van Horssen et al., 2008) and oxidized DNA in their nuclei (Haider et al., 2011). Accumulation of oxidative stress suggests that these glia can no longer support neurons (Lin et al., 2007) which could lead to decreased neuronal function and damage as seen in the disease. However, whether this damaging mechanism really does occur in MS is unknown because astrocytes in active MS white matter (WM) lesions also augment expression of mitochondrial antioxidants (Nijland et al., 2014; LichtMayer et al., 2015; Lassmann and van Horssen, 2016). More specifically, enhanced expression of peroxisome proliferatoractivated receptor-gamma coactivator 1-alpha (PGC-1 $\alpha$ ) was observed in reactive astrocytes, and astrocytes that over-express PGC- $1 \alpha$ not only secrete less pro-inflammatory cytokines and chemokines, but they protect neuronal cells against oxidative attack greater than those co-cultured with control astrocytes (Nijland et al., 2014). Further, Nuclear factor erythroid 2-related factor 2 and its stabilizer and positive regulator, DJ1, is another antioxidant that is increased in reactive astrocytes in both active and chronic active MS lesions (van Horssen et al., 2010), and found to be protective against ROS in co-cultured neurons (Shih et al., 2003; Kraft et al., 2004; Calkins et al., 2005). Altogether, these findings imply that astrocytes are actively trying to combat oxidative damage both within themselves and neighboring cells, but their protective measures are insufficient to combat the overwhelming oxidative damage occurring with age and during age-associated neurodegenerative diseases.

\section{Aged Astrocytes and Peptidase Inhibition}

Serine proteases control many key elements of the immune system including granzymes which activate apoptotic pathways, complement system proteins that mediate inflammation and phagocytosis, and production of cytokines and chemokines (Safavi and Rostami, 2012). These proteases have been linked to aging. For example, an increase in serine protease HTRA1 in mouse retinal pigment epithelium may contribute to age-related macular degeneration due to degeneration of the epithelium (Jones et al., 2011). Further, a significant increase in the serine proteases plasmin, trypsin and elastase was found in the blood of aged rats and appear to be involved in extracellular matrix degradation (Paczek et al., 2009). In aged astrocytes, serine protease inhibitor called Serpina3n is significantly upregulated (Boisvert et al., 2018; Clarke et al., 2018) which may be an attempt by aged astrocytes to combat the aging effects of serine proteases.

\section{Cholesterol Synthesis}

Due to the BBB, the CNS does not uptake cholesterol from the blood stream, and instead has to locally synthesize the majority of cholesterol that it needs. Astrocytes are believed to play a major role in brain cholesterol synthesis because of their expression of sterol regulatory element-binding protein 2 (SREBP2; Ferris et al., 2017). SREBP2 activates the transcription of enzymes, including HMG-CoA reductase (Hmgcr), that are needed for cholesterol synthesis and cholesterol uptake receptors, including the LDL receptor (Madison, 2016). SREBP2 presence in astrocytes is critical for CNS function since its knockout in astrocytes in mice results in impaired brain development and function and reduced neurite outgrowth (Ferris et al., 2017). In the aged murine brain, the rate limiting cholesterol synthesis enzyme Hmgcr is downregulated, while the receptors for cholesterol transport are increased in astrocytes (Boisvert et al., 2018). This suggests that there is an overall dysregulation of the cholesterol synthesis pathway in astrocytes, and since many cells, including neurons, rely on cholesterol from astrocytes (Zhang et al., 2016), this dysregulation may lead to metabolic disruption in these nerve cells.

\section{Epigenetics of Aging Astrocytes}

Studies that have looked at overall methylation changes during aging have shown that both hyper- and hypo-methylation occur with age at comparable rates (Maegawa et al., 2010; Issa, 2014). In addition, histone modification has also been shown to occur in aging cells (Wood et al., 2010; Liu et al., 2013). DNA methylation is an important process in the development of astrocytes since demethylation of astrocyte-specific genes such as GFAP, S100 $\beta$ and Aqp4 in neural stem cells (NSCs) promotes the switch from neurogenesis to astrogenesis (Namihira et al., 2004, 2009; Hatada et al., 2008; Takouda et al., 2017). In mature astrocytes, global DNA methylation patterns have been shown to occur in psychiatric disorders (Nagy et al., 2015) and alcohol use (Miguel-Hidalgo, 2018), however our understanding of epigenetic changes in astrocytes during aging is limited. Chrisholm and colleagues noted that H3K4 specific methyltransferase activity was lower in astrocytes from middle aged vs. young female rats following ischemia (Chisholm et al., 2015). As such, they proposed that future therapies may be able to target epigenetic modifications to provide neuroprotection against aging in astrocytes (Chisholm et al., 2015). Indeed, it has been suggested that inhibitors of histone deacetylases (HDACs) may be neuroprotective via effects on glial cells (Staszewski and Prinz, 2014). Some evidence in support of this presumption was seen in astrocyte cultures where it was shown that HDAC inhibition increased neurotrophic cytokines (Chen et al., 2006) and mitigated changes in Parkinson's and Alzheimer's disease (PD and AD; Nuutinen et al., 2010), although no changes were seen in reducing astrocyte activation (Xuan et al., 2012).

Environmental factors can also induce epigenetic changes. In a recent study that assessed how environment impacted young vs. old astrocytes, it was reported that aged mice from a standard environment could not distinguish between stationary and displaced objects (Diniz et al., 2016). Upon further examination of the astrocytes in these animals, the authors found two distinct morphological phenotypes and speculated that aging and environment reduce the complexity of astrocytes (Diniz et al., 2016). This agrees with previous literature showing 
morphological changes between young and old astrocytes (Kanaan et al., 2010; Cerbai et al., 2012; Jyothi et al., 2015). Furthermore, disturbances in astrocyte mitochondrial function have been shown to occur with age and these changes can also be seen when astrocytes are exposed to environmental neurotoxicants such as 3-chloropropanediol (Cavanagh et al., 1993), 1-methyl-4-phenyl-1,2,3,6-tetrahydropyridine (MPTP; Sundar Boyalla et al., 2011) and manganese (Zheng et al., 1998).

\section{Blood Brain Barrier (BBB) and Aged Astrocytes}

The BBB consists of endothelial cells, astrocytic endfeet processes, pericytes, smooth muscle cells, neurons and perivascular microglia (Abbott and Friedman, 2012; Banks, 2016; Osipova et al., 2018). Considering that the BBB is comprised of such a variety of cell types, it is evident that disturbances in any one of these cells could result in changes to BBB integrity. The $\mathrm{BBB}$ is a compact complex held together by tight junctions which limits the diffusion of molecules and migration of cells from freely entering and exiting the brain. Transport of substances and cells that are required for CNS homeostasis occurs mainly by transcellular routes and acquisition of small molecules requires expression of specific transporters in order to pass across the BBB (Goodall et al., 2018).

As mentioned, astrocytes are an integral part of the $\mathrm{BBB}$ as they are involved in its development, maintenance and regulation. For example, astrocytes secrete Sonic Hedgehog (Shh) while BBB-endothelial cells bear the receptor for Shh (Alvarez et al., 2011). Blocking the Hedgehog pathway in astrocytes was found to increase barrier permeability while a lack of Shh led to compromisation of the barrier phenotype (Alvarez et al., 2011). Astrocytes also secrete a variety of factors that influence the function and permeability of the BBB. For instance, inflammatory factors such as nitric oxide, IL-6, TNF- $\alpha$ and matrix metalloproteinases, which astrocytes are known to secrete when they acquire an inflammatory state, have been shown to impair vasculature control and function (Zhang, 2008). A common pathway that is involved in the production of these inflammatory factors includes the NF- $\kappa \mathrm{B}$ pathway, which has been shown to have a direct effect on the tight junction proteins occludin, ZO-1 and claudin-5 (Lamberti et al., 2001; Stamatovic et al., 2008; Aveleira et al., 2010). It is also important to note however, that astrocytes can also be protective in $\mathrm{BBB}$ function. This includes the NF-кB pathway, which has been shown to promote barrier function by inducing the expression of Shh (Kasperczyk et al., 2009).

$\mathrm{BBB}$ changes have been documented in neurodegenerative diseases, which are typically associated with age progression (Kirk et al., 2003; Zlokovic, 2008). However, changes in BBB permeability with age are conflicting as some groups have shown an increase in permeability with age (Mooradian and McCuskey, 1992; Hosokawa and Ueno, 1999; Kirk et al., 2003; HafeziMoghadam et al., 2007; Farrall and Wardlaw, 2009; Popescu et al., 2009; Goodall et al., 2018) while others have shown no alteration (Wadhwani et al., 1991; Vorbrodt and Dobrogowska, 1994;
Banks et al., 2000; Mackic et al., 2002). Due to this dichotomy, further research needs to be done to clarify the changes that are occurring with age, and specifically how the aged astrocyte contributes to these changes. Based on the changes that we know occur in aging astrocytes we can speculate that if there is age-dependent $\mathrm{BBB}$ alterations, aged astrocytes could contribute to any phenotype and permeability impairment because of their inflammatory secretions.

\section{Chronodisruption and Aged Astrocytes}

An interesting observation about aged astrocytes is their association with chronodisruption. Circadian rhythm generates a time clock to a $24 \mathrm{~h}$ cycle that influences our behavior and physiology and adapts us to light/dark cycles of the earth (Kondratova and Kondratov, 2012; Hood and Amir, 2017). Our circadian rhythm is generated in the suprachiasmatic nucleus (SCN) of the hypothalamus via a transcriptional/translational feedback loop (Golombek and Rosenstein, 2010; Duhart et al., 2013). Briefly, the loop begins when transcription factors, CLOCK and BMAL1 heterodimerize and initiate transcription of Per and Cry genes. PER and CRY proteins form a complex in the cytoplasm and block transcription of CLOCK/BMAL1, which in turn inhibits transcription of Per and Cry. PER/CRY complex is also targeted for degradation via the proteasomal pathway, which initiates the transcription of CLOCK/BMAL1 again. This feedback loop forms the core oscillator mechanism (Lowrey and Takahashi, 2011; Duhart et al., 2013). The SCN is composed of a variety of classes of neurons and astrocytes (Abrahamson and Moore, 2001). Recent work has demonstrated that SCN neurons are metabolically active during daytime while SCN astrocytes are active during night and that these astrocytes are able to suppress the activity of SCN neurons through extracellular glutamate (Brancaccio et al., 2017).

Disruption of circadian rhythm has been suggested to be carcinogenic to humans (Straif et al., 2007) and has been well documented to be altered during aging and neurodegenerative diseases of aging (Kondratova and Kondratov, 2012; Mattis and Sehgal, 2016). Oxidative stress has not only been proposed as a mechanism of aging, and is indeed a common feature amongst aging neurodegenerative diseases, but it is speculated to contribute to changes in circadian rhythm with age (Grimm et al., 2011; Kondratova and Kondratov, 2012; Krishnan et al., 2012). As discussed above, oxidative stress negatively impacts astrocytes by reducing their ability to support neurons. Because the neuronastrocyte relationship is integral in the SCN, disruption of proteins in the SCN could perturb this collaboration. Indeed and for example, BMAL1 deletion in SCN neurons can cause partial astrocyte activation, while BMAL1 deletion in SCN astrocytes induced astrogliosis and astrocyte dysfunction (Lananna et al., 2018). In addition, circadian disruption can induce GFAP expression (Lananna et al., 2018), while aging (Wyse and Coogan, 2010) and inflammation (Curtis et al., 2015) have been shown to suppress BMAL1 levels, thus potentially influencing astrocyte activation state as well (Lananna et al., 2018). However, loss of BMAL1 in astrocytes does not disrupt circadian rhythm (Tso et al., 2017). Instead, it was found that deletion of CK1 1 , an enzyme that controls phosphorylation of PER/CRY in SCN 


\section{A \\ Phenotype}
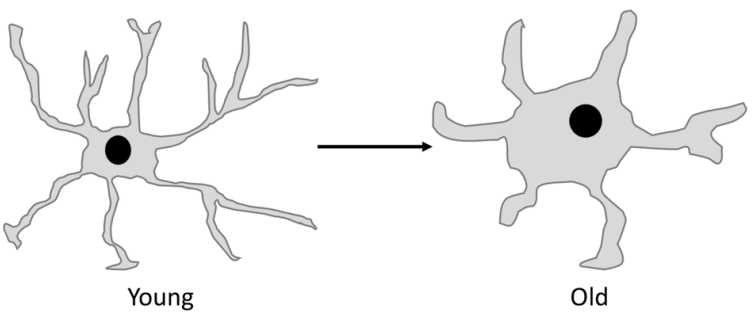

B

Molecular Profile of Aged Astrocytes Upregulated

\begin{tabular}{|c|c|}
\hline Reactivity & $\begin{array}{l}\text { - } \quad \text { GFAP } \\
\text { - } \quad \text { "A1" genes }\end{array}$ \\
\hline Complement System & $\begin{array}{l}-\mathrm{C} 3 \mathrm{~b} \\
-\mathrm{C} 4\end{array}$ \\
\hline Antigen Presentation & $\begin{array}{ll}\cdot & \text { H2-K1 } \\
\text { - } & \text { H2-D1 } \\
\text { - } & \text { Pros1 } \\
\text { - } & \text { Mfge8 } \\
\text { - } & \text { Megf10 } \\
\text { - } & \text { Lrp1 }\end{array}$ \\
\hline Secretory Molecules & $\begin{array}{ll}\text { - } & \text { CXCL10 } \\
\text { - } & \text { CXCL5 }\end{array}$ \\
\hline Oxidative Stress & $\begin{array}{ll}\text { - } & \text { ROS } \\
\text { - } & \text { MAPK }\end{array}$ \\
\hline Peptidase Inhibition & - Serpin3a \\
\hline Cholesterol Synthesis & $\begin{array}{l}\text { - Cholesterol transport } \\
\text { receptors }\end{array}$ \\
\hline
\end{tabular}

Downregulated

\begin{tabular}{|l|l|}
\hline Secretory Molecules & $\bullet$ ATP \\
& $\cdot$ VEGF \\
& $\cdot$ FGF2 \\
\hline Oxidative Stress & BDNF \\
& $\cdot$ PGC1- $\alpha$ \\
& $\cdot$ Drf2 \\
\hline Cholesterol Synthesis & $\bullet$ Hmgcr \\
\hline Epigenetics & - H3K4 specific methyl- \\
& transferase \\
\hline
\end{tabular}

FIGURE 1 | Schematic representation that summarize the phenotype change of astrocytes as they age (A) and the molecular profile of aged astrocytes (B).

astrocytes, resulted in an increase in behavioral period in mice (Tso et al., 2017). These results suggest a feedback loop involving astrocytes and neurons in circadian rhythm impairment. That is, the reciprocal relationship between astrocyte and neurons in the SCN suggests that a disruption in astrocytes would in turn affect neurons resulting in disruption of the feedback loop.

\section{Summary}

The majority of changes in aged astrocytes may be fueling the pro-inflammatory processes that occur with aging-albeit there are instances (e.g., serine protease inhibition) where aged astrocytes are trying to combat detrimental mechanisms
(Figure 1). Since the majority of these alterations are of the pro-inflammatory nature, it appears that the anti-inflammatory processes within astrocytes and other CNS cells are inadequate to quell the inflammatory properties, thus contributing to a heightened inflammatory state as we age. It is likely also that the enhanced expression of pro-inflammatory changes in aged astrocytes has effects beyond these glia by influencing the function of other CNS cells, the subject of the next section.

\section{AGED ASTROCYTES AND OTHER CNS CELLS}

\section{Microglia}

It was a long-held dogma that glial cells only provided support to neurons, however recent research suggests a much more complex and active interplay between glial cells themselves and their relationship with neurons. While more work is needed to definitively elucidate the relationship between different glial cells during aging, there are some insights into what is occurring amongst these cells during senescence. In a model of aging neuroinflammation in the hippocampus, astrocyte branches were found to be actively bisecting the cell body of neurons while microglia contained neuronal debris (Cerbai et al., 2012), suggesting that astrocytes and microglia may both be involved in eliminating neurons during aging. Whether these are joint efforts or each cell performing their function autonomously is however unclear. Recent work from the Barres lab demonstrated that activated microglia are able to influence astrocyte activation through their secretory profile (e.g., C1q, TNF- $\alpha$ and IL- $1 \alpha$; Liddelow et al., 2017) implying that microglia could influence astrocyte activation during inflammation. In the context of aging, microglia have been shown to increase their reactivity (Hickman et al., 2013; Norden and Godbout, 2013; Grabert et al., 2016), which would suggest that they would augment their secretory profile. There is some support for this idea since it has been shown that the increase in reactive astrocyte genes associated with aging was significantly reduced in mice lacking C1q, TNF$\alpha$ and IL-1 $\alpha$ (Clarke et al., 2018). Of no surprise, this feedback loop between microglia and astrocytes is also present when trying to resolve inflammation, of which becomes disrupted in the aging brain. More specifically, activated microglia secrete the anti-inflammatory cytokine IL-10. Astrocytes express the IL-10 receptor (IL-10R) and upon activation of this receptor, secrete TGF- $\beta$, which in turn decreases microglial activation (Norden et al., 2014). However, aged astrocytes do not increase their expression of IL-10R or secretion of TGF- $\beta$, which would release the brakes needed to suppress astrocyte and microglial activation during aging (Norden et al., 2014). Therefore, astrocytes and microglia function both autonomously and non-autonomously in aging and age-related neurodegenerative disorders to contribute to neuronal loss and inflammaging of the brain (Franceschi et al., 2007).

\section{Neurons}

Astrocytes support neuronal function in many ways including ion homeostasis, metabolic support and transmitter homeostasis (Sofroniew and Vinters, 2010). As mentioned previously, 
neuronal numbers do not change with age (Cragg, 1975; Terry et al., 1987; Freeman et al., 2008), but their function and morphology change with age (Pannese, 2011). This led researchers to explore whether age-related changes in astrocytes could impact neuronal function. Indeed, astrocytes gain an "A1" phenotype with age, and previous work with this phenotype found that "A1" astrocytes secrete a neurotoxin that kills neurons (Liddelow et al., 2017). In addition, aging astrocytes increase expression of Sparc (Boisvert et al., 2018), which blocks synapse formation and decreases $\alpha$-amino-3-hydroxy-5-methyl4-isoxazolepropionic acid receptors (Nobuta et al., 2012; Allen, 2014) thereby potentially inhibiting synapse function of neurons. As mentioned previously also, upregulation of the complement system factors, C3 and C4B in aged astrocytes, suggests that these glia have the potential to eliminate neuronal synapses (Boisvert et al., 2018; Clarke et al., 2018). Finally, disruption in lipid metabolism (see "Cholesterol Synthesis" section) could lead to impaired synapse formation and function of neurons (van Deijk et al., 2017). However, it should be noted that the majority of astrocyte homeostatic functions involved in neuronal support are unaltered with age, including genes involved in ion, glutamate and lactate regulation (Boisvert et al., 2018). This suggests that astrocytes are still capable of supporting certain neuronal functions with age and thus the balance between the various beneficial and detrimental effects will determine the health of a neuron. For instance, although the majority of astrocyte support of neuronal cells is not altered, the changes that occur in every aged cell (neuron, microglia, OL) that influence neuronal function may eventually add up and tip the balance towards an impaired neuron.

\section{Oligodendrocytes}

In regard to OLs, there is some evidence that astrocyte dysfunction with age could negatively impact the function of these cells. OLs synthesize myelin and wrap axons that are seen as WM in the brain and spinal cord. Aging results in a 30\% decrease in $\mathrm{WM}$ and a $45 \%$ decrease in myelinated fiber length from the age of 20-80 years old (Bartzokis et al., 2001; Marner et al., 2003). While myelin production still occurs as we age, aging results in thinner myelin sheaths and shorter internodes (Marner et al., 2003) that can be traced back to OL dysfunction. The hypothesis is that due to oxidative stress, OLs suffer from DNA damage that accumulates during aging to result in WM changes (Tse and Herrup, 2017). In addition to OLs, precursors for these glia may also contribute to the WM changes with age. In the mature CNS, a pool of progenitor cells known as OL progenitor cells (OPCs) reside to serve as replacements for OLs. While the OPC pool remains constant throughout age (Boda et al., 2015) there is an inherent defect in their differentiation with senescence. Their differentiation time is doubled (Zhu et al., 2011) and there is an impairment in their recruitment to replace OLs (Doucette et al., 2010).

Astrocytes are known to support OL function including proliferation, differentiation and myelination. While OLs synthesize cholesterol to produce myelin they also rely on cholesterol synthesis from astrocytes for their myelin production; however, as discussed above, cholesterol synthesis is impaired in aging astrocytes. As a consequence, OLs may not receive the necessary amount of cholesterol during aging, thus resulting in reduced myelin production characteristic of the aging brain. Another process of OLs that aged astrocytes may disrupt is differentiation. Before OLs can produce myelin they need to undergo differentiation from their OPC state. FGF2, an important factor in OPC differentiation (Bögler et al., 1990), is decreased in aged astrocytes (Bernal and Peterson, 2011), suggesting that astrocytes may hinder the differentiation process.

In contrast to the detrimental effects aging astrocytes may have on OLs and OPCs, they may also be potentially beneficial. Astrocytes increase their expression of CXCL10, which is involved in the migration of OPCs (Omari et al., 2005), and an increase in the inflammatory state of aging astrocytes coincides with an increase in STAT3 (Monteiro de Castro et al., 2015), that may be in involved in crosstalk with microglia and OPCs to prevent impairment of OPC maturation (Nobuta et al., 2012). It is possible however, while these mechanisms are integral in recruiting OPCs to sites that need OL repopulation and differentiation, the astrocyte-contributing defects in differentiation and reduced myelin production may overcome these beneficial properties of aged astrocytes on OL functions.

\section{Summary}

The interactions of aged astrocytes with other CNS cell populations suggest that they can propagate inflammation and directly affect the health and function of these other cells

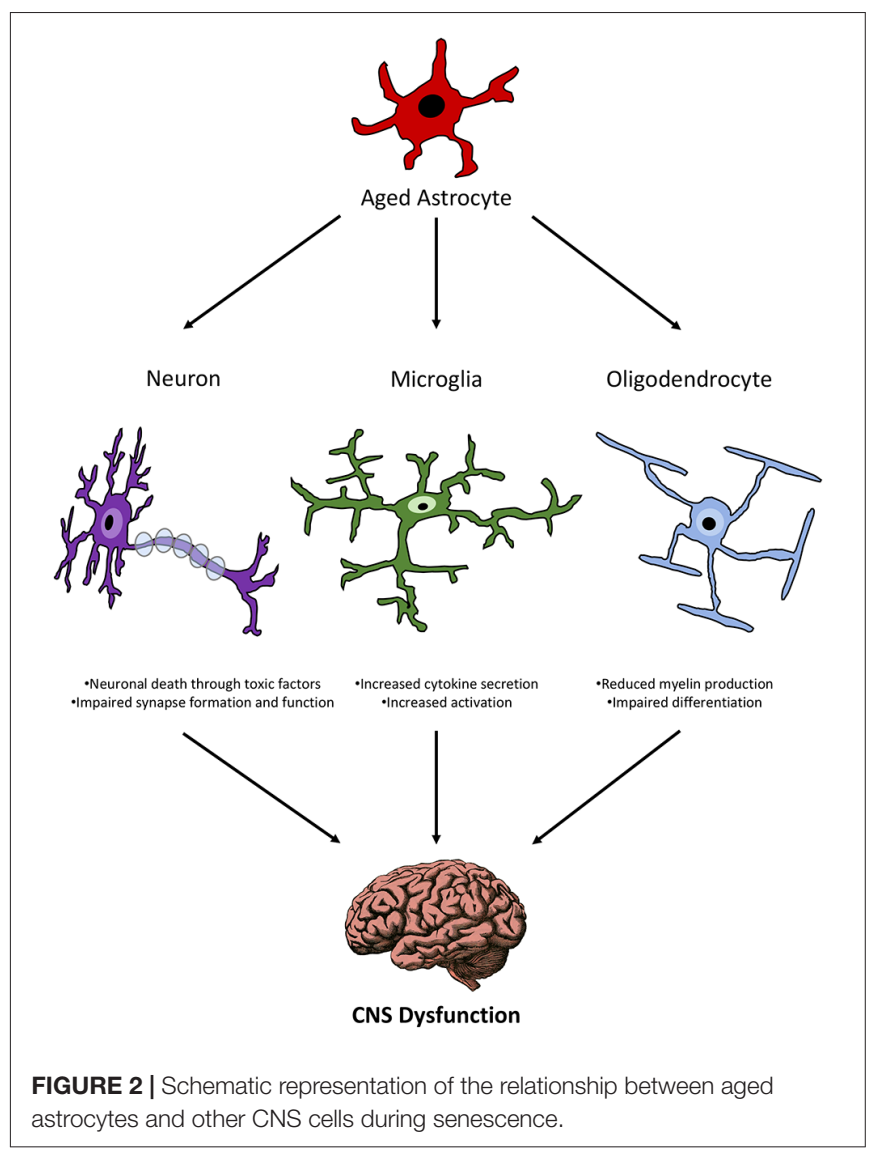


(Figure 2). Since all of these cells communicate with each other, a direct effect of astrocyte interactions with any one of these cell populations can create a feedback loop that results in the dysfunction of multiple cell types and ultimately functional impairment as seen in age-related diseases.

\section{AGED ASTROCYTES AND NEURODEGENERATIVE DISEASES}

In 2015, the aged population (aged 65 and over) represented $8.5 \%$ (or 617.1 million) of the total population (He et al., 2016). By 2050, it is predicted that the aging population will rise to over $16.7 \%$ or 1.6 billion ( $\mathrm{He}$ et al., 2016). That is a $150 \%$ expansion of the aged population (He et al., 2016). With age comes an increased risk for age-related diseases, which includes neurodegenerative diseases. Aging and neurodegeneration share many features including gliosis, loss of myelination, cognitive decline, loss of working memory and astrocyte dysfunction. $\mathrm{AD}, \mathrm{PD}$ and amyotrophic lateral sclerosis (ALS) are three common age-related diseases known to have astrocyte involvement. There are many in-depth reviews on $\mathrm{AD}, \mathrm{PD}$ and ALS and thus we will limit our discussion to what is known about the role of astrocytes in these diseases.

\section{$A D$ and Astrocytes}

$\mathrm{AD}$ affects more than 35 million people worldwide and is the most frequent form of dementia in the aged population, accounting for $50 \%-56 \%$ of cases (Querfurth and LaFerla, 2010). Aging does not mean individuals will progress to $\mathrm{AD}$, however, $\mathrm{AD}$ and aging share many common features including oxidative stress, mitochondrial dysfunction, inflammation, proteotoxicity and altered gene expression (Chakrabarti and Mohanakumar, 2016). These common features can also be found in $\mathrm{AD}$ astrocytes. For example, neurons in $\mathrm{AD}$ have been shown to increase insulin-like growth factor 1 (IGF-1) via astrocyte interactions, which can lead to increased beta-amyloid formation by neurons (Costantini et al., 2010). Beta-amyloid, in turn, is capable of stimulating astrocytes and causing activation of NF- $\kappa \mathrm{B}$ pathways (considered an important mediating agent in neuroinflammation in AD; Akama and Van Eldik, 2000; Wang et al., 2013; Shi et al., 2016) and consequently production of pro-inflammatory cytokines such as IL-1 $\beta$, IL-6, iNOS and TNF- $\alpha$ (Bales et al., 1998; Akama and Van Eldik, 2000; Hou et al., 2011). Other evidence of astrocyte involvement in AD pathogenesis is a decline in antioxidant defense, which could result in the accumulation of oxidative damage in astrocytes leading to neurodegeneration (Hung et al., 2010). For example, oxidative stress can result in activation of astrocytes (Andersen, 2004) and activation of NADPH oxidase in astrocytes, which has been shown to lead to beta-amyloid-induced neuronal death through mitochondrial dysfunction (Abramov et al., 2004).

\section{Astrocytes and PD}

$\mathrm{PD}$ is the second most common age-related disease after $\mathrm{AD}$ (Reeve et al., 2014). Age is the strongest risk factor for PD, with prevalence of the disease increasing more than 400 times as one ages (Rodriguez et al., 2015). Although volume reduction can be seen throughout the aging brain, the substantia nigra dopaminergic neurons are particularly affected in PD displaying neuronal loss at a rate of $4.7 \%$ to $9.8 \%$ per decade (Fearnley and Lees, 1991; Ma et al., 1999; Rudow et al., 2008). It is incompletely known why dopaminergic neurons are targeted, but it has been suggested that astrocytes may be involved. Astrocytes and neurons share a very close relationship due to the fact that astrocytes are part of the tripartite synapse, provide structural and metabolic support, buffer neurotransmitters, and help regulate synaptic transmission (Sofroniew and Vinters, 2010). Because these functions become compromised in the aged astrocyte, it is likely that neuronal health would be directly impacted. Furthermore, genes that have been identified as part of astrocyte biology are also causative in the development of PD; these include PARK7, SNCA, PLA2G6, ATP13A2, LRRK2, GBA, PINK1 and PARK2 (Zhang et al., 2016; Booth et al., 2017). These genes are involved in a variety of functions in astrocytes including inflammatory responses, cholesterol synthesis, and mitochondrial dysfunction which are also known to be dysfunctional in PD.

\section{ALS and Astrocytes}

ALS is a degenerative disease of motor neurons in the brain, brain stem and spinal cord, that leads to paralysis and death (Rowland and Shneider, 2001). Although ALS is not considered a prototypical aging disease, the median age of onset occurs at 70.8 years of age in European populations (Marin et al., 2014) and has an incidence curve similar to that of PD (Logroscino et al., 2015). In addition, recent genetic advances have revealed that pathways involved in the development of the disease are also modulated during the aging process. These include autophagy, inflammation and cellular maintenance (Niccoli et al., 2017). The precise mechanisms that target motor neurons in ALS remain elusive. However, it has been proposed that during aging in rodents a loss of astrocytic support to motor neurons may result in loss of both motor neurons and their function (Das and Svendsen, 2015; Das et al., 2016). This loss of support is further accelerated in a rodent model of ALS (Das and Svendsen, 2015). Furthermore, astrocytes generated from post-mortem brain tissue from both familial and sporadic ALS are toxic to motor neurons and a knockdown of the superoxide dismutase 1 gene in astrocytes, a known genetic risk factor in ALS, attenuates this toxicity (Haidet-Phillips et al., 2011). In addition, treatment of motor neuron/astrocyte co-cultures with an inhibitor for necrotic cell death prevented loss of motor neurons (Re et al., 2014). It appears that the $\mathrm{NF}-\kappa \mathrm{B}$ signaling pathway in astrocytes may be participating in the astrocyte-motor neuron death (Haidet-Phillips et al., 2011).

\section{Summary}

The general inflammatory state of astrocytes gives us a good prediction of different processes that may become dysfunctional during disease. By exploring how this inflammatory state is 
manipulated or altered in various age-related neurodegenerative disorders, we can gain better insight into potential disease mechanisms and pathology.

\section{CONCLUSION}

In conclusion, a growing number of studies have shown that astrocytes play a more central role than previously appreciated in aging and age-related diseases. These glia become more pro-inflammatory and contribute to the general low-grade inflammation that is characteristic of the aging brain. Further, because of their active interactions and secretory products, aged astrocytes could negatively afflict other CNS cells. Further work is needed to unravel how these glia interact with other

\section{REFERENCES}

Abbott, N. J., and Friedman, A. (2012). Overview and introduction: the bloodbrain barrier in health and disease. Epilepsia 53, 1-6. doi: 10.1111/j.1528-1167. 2012.03696.x

Abrahamson, E. E., and Moore, R. Y. (2001). Suprachiasmatic nucleus in the mouse: retinal innervation, intrinsic organization and efferent projections. Brain Res. 916, 172-191. doi: 10.1016/s0006-8993(01) 02890-6

Abramov, A. Y., Canevari, L., and Duchen, M. R. (2004). $\beta$-amyloid peptides induce mitochondrial dysfunction and oxidative stress in astrocytes and death of neurons through activation of NADPH oxidase. J. Neurosci. 24, 565-575. doi: 10.1523/jneurosci.4042-03.2004

Adrover, J. M., Nicolás-Ávila, J. A., and Hidalgo, A. (2016). Aging: a temporal dimension for neutrophils. Trends Immunol. 37, 334-345. doi: 10.1016/j.it. 2016.03.005

Akama, K. T., and Van Eldik, L. J. (2000). $\beta$-amyloid stimulation of inducible nitric-oxide synthase in astrocytes is interleukin-1 $\beta$ - and tumor necrosis factor$\alpha(\mathrm{TNF} \alpha)$-dependent and involves a TNF $\alpha$ receptor-associated factor- and NFKB-inducing kinase-dependent signaling mechanism. J. Biol. Chem. 275, 7918-7924. doi: 10.1074/jbc.275.11.7918

Allen, N. J. (2014). Astrocyte regulation of synaptic behavior. Annu. Rev. Cell Dev. Biol. 30, 439-463. doi: 10.1146/annurev-cellbio-100913-0 13053

Alvarez, J. I., Dodelet-Devillers, A., Kebir, H., Ifergan, I., Fabre, P. J., Terouz, S., et al. (2011). The Hedgehog pathway promotes blood-brain barrier integrity and CNS immune quiescence. Science 334, 1727-1731. doi: 10.1126/science. 1206936

Amenta, F., Bronzetti, E., Sabbatini, M., and Vega, J. A. (1998). Astrocyte changes in aging cerebral cortex and hippocampus: a quantitative immunohistochemical study. Microsc. Res. Tech. 43, 29-33. doi: 10.1002/ (SICI)1097-0029(19981001)43:1<29::AID-JEMT5>3.0.CO;2-H

Andersen, J. K. (2004). Oxidative stress in neurodegeneration: cause or consequence? Nat. Med. 10, S18-S25. doi: 10.1038/nrn1434

Aveleira, C. A., Lin, C.-M., Abcouwer, S. F., Ambrósio, A. F., and Antonetti, D. A. (2010). TNF- $\alpha$ signals through PKC $\zeta / N F-\kappa B$ to alter the tight junction complex and increase retinal endothelial cell permeability. Diabetes 59, 2872-2882. doi: $10.2337 / \mathrm{db} 09-1606$

Bales, K. R., Du, Y., Dodel, R. C., Yan, G. M., Hamilton-Byrd, E., and Paul, S. M. (1998). The NF- $\mathrm{B} /$ Rel family of proteins mediates $\mathrm{A} \beta$ induced neurotoxicity and glial activation. Mol. Brain Res. 57, 63-72. doi: 10.1016/s0169-328x(98)00066-7

Banks, W. A. (2016). From blood-brain barrier to blood-brain interface: new opportunities for CNS drug delivery. Nat. Rev. Drug Discov. 15, 275-292. doi: $10.1038 / \mathrm{nrd} .2015 .21$

Banks, W. A., Farr, S. A., and Morley, J. E. (2000). Permeability of the bloodbrain barrier to albumin and insulin in the young and aged SAMP8 mouse. J. Gerontol. A Biol. Sci. Med. Sci. 55, B601-B606. doi: 10.1093/gerona/55. $12 . \mathrm{b} 601$
CNS cells at the cellular and molecular level since this will have implications when developing therapeutics for age-related diseases.

\section{AUTHOR CONTRIBUTIONS}

$\mathrm{SO}$ and $\mathrm{AP}$ conceived and wrote the manuscript.

\section{FUNDING}

This work was funded by operating grants to SO from the Canadian Institutes of Health Research (MOP-136890) and the Multiple Sclerosis Society of Canada (MSSOC; EGID 1994).

Bartzokis, G., Beckson, M., Lu, P. H., Nuechterlein, K. H., Edwards, N., and Mintz, J. (2001). Age-related changes in frontal and temporal lobe volumes in men: a magnetic resonance imaging study. Arch. Gen. Psychiatry 58, 461-465. doi: 10.1001/archpsyc.58.5.461

Beckman, K. B., and Ames, B. N. (1998). The free radical theory of aging matures. Physiol. Rev. 78, 547-581. doi: 10.1152/physrev.1998.78.2.547

Bellaver, B., Souza, D. G., Souza, D. O., and Quincozes-Santos, A. (2017). Hippocampal astrocyte cultures from adult and aged rats reproduce changes in glial functionality observed in the aging brain. Mol. Neurobiol. 54, 2969-2985. doi: 10.1007/s12035-016-9880-8

Berchtold, N. C., Cribbs, D. H., Coleman, P. D., Rogers, J., Head, E., Kim, R., et al. (2008). Gene expression changes in the course of normal brain aging are sexually dimorphic. Proc. Natl. Acad. Sci. U S A 105, 15605-15610. doi: 10.1073/pnas.0806883105

Bernal, G. M., and Peterson, D. A. (2011). Phenotypic and gene expression modification with normal brain aging in GFAP-positive astrocytes and neural stem cells. Aging Cell 10, 466-482. doi: 10.1111/j.1474-9726.2011.00694.x

Boda, E., Di Maria, S., Rosa, P., Taylor, V., Abbracchio, M. P., and Buffo, A. (2015). Early phenotypic asymmetry of sister oligodendrocyte progenitor cells after mitosis and its modulation by aging and extrinsic factors. Glia 63, 271-286. doi: 10.1002/glia.22750

Bögler, O., Wren, D., Barnett, S. C., Land, H., and Noble, M. (1990). Cooperation between two growth factors promotes extended self-renewal and inhibits differentiation of oligodendrocyte-type- 2 astrocyte (O-2A) progenitor cells. Proc. Natl. Acad. Sci. U S A 87, 6368-6372. doi: 10.1073/pnas.87.16.6368

Boisvert, M. M., Erikson, G. A., Shokhirev, M. N., and Allen, N. J. (2018). The aging astrocyte transcriptome from multiple regions of the mouse brain. Cell Rep. 22, 269-285. doi: 10.1016/j.celrep.2017.12.039

Booth, H. D. E., Hirst, W. D., and Wade-Martins, R. (2017). The role of astrocyte dysfunction in Parkinson's disease pathogenesis. Trends Neurosci. 40, 358-370. doi: 10.1016/j.tins.2017.04.001

Brancaccio, M., Patton, A. P., Chesham, J. E., Maywood, E. S., and Hastings, M. H. (2017). Astrocytes control circadian timekeeping in the suprachiasmatic nucleus via glutamatergic signaling. Neuron 93, 1420.e5-1435.e5. doi: 10.1016/j.neuron.2017.02.030

Brawek, B., Löffler, M., Wagner, K., Huppertz, H. J., Wendling, A. S., Weyerbrock, A., et al. (2010). Reactive oxygen species (ROS) in the human neocortex: role of aging and cognition. Brain Res. Bull. 81, 484-490. doi: 10.1016/j.brainresbull.2009.10.011

Brody, H. (1955). Organization of the cerebral cortex. III. A study of aging in the human cerebral cortex. J. Comp. Neurol. 102, 511-516. doi: 10.1002/cne. 901020206

Calkins, M. J., Jakel, R. J., Johnson, D. A., Chan, K., Kan, Y. W., and Johnson, J. A. (2005). Protection from mitochondrial complex II inhibition in vitro and in vivo by Nrf2-mediated transcription. Proc. Natl. Acad. Sci. U S A 102, 244-249. doi: 10.1073/pnas.0408487101

Castiglioni, A. J., Legare, M. E., Busbee, D. L., and Tiffany-Castiglioni, E. (1991). Morphological changes in astrocytes of aging mice fed normal or caloric restricted diets. Age 14, 102-106. doi: 10.1007/bf02435015 
Cavanagh, J. B., Nolan, C. C., and Seville, M. P. (1993). The neurotoxicity of $\alpha-$ chlorohydrin in rats and mice: I. Evolution of the cellular changes. Neuropathol. Appl. Neurobiol. 19, 240-252. doi: 10.1111/j.1365-2990.1993.tb00434.x

Cerbai, F., Lana, D., Nosi, D., Petkova-Kirova, P., Zecchi, S., Brothers, H. M., et al. (2012). The neuron-astrocyte-microglia triad in normal brain ageing and in a model of neuroinflammation in the rat hippocampus. PLoS One 7:e45250. doi: 10.1371/journal.pone.0045250

Chakrabarti, S., and Mohanakumar, K. P. (2016). Aging and neurodegeneration: a tangle of models and mechanisms. Aging Dis. 7, 111-113. doi: 10.14336/ad. 2016.0312

Chen, P.-S., Peng, G.-S., Li, G., Yang, S., Wu, X., Wang, C.-C., et al. (2006). Valproate protects dopaminergic neurons in midbrain neuron/glia cultures by stimulating the release of neurotrophic factors from astrocytes. Mol. Psychiatry 11, 1116-1125. doi: 10.1038/sj.mp.4001893

Chisholm, N. C., Henderson, M. L., Selvamani, A., Park, M. J., Dindot, S., Miranda, R. C., et al. (2015). Histone methylation patterns in astrocytes are influenced by age following ischemia. Epigenetics 10, 142-152. doi: 10.1080/15592294.2014.1001219

Choi, J.-H., Sim, S.-E., Kim, J.-I., Choi, D. I., Oh, J., Ye, S., et al. (2018). Interregional synaptic maps among engram cells underlie memory formation. Science 360, 430-435. doi: 10.1126/science.aas9204

Clarke, L. E., Liddelow, S. A., Chakraborty, C., Munch, A. E., Heiman, M., and Barres, B. A. (2018). Normal aging induces A1-like astrocyte reactivity. Proc. Natl. Acad. Sci. U S A 115, E1896-E1905. doi: 10.1073/pnas.18001 65115

Coleman, P. D., and Flood, D. G. (1987). Neuron numbers and dendritic extent in normal aging and Alzheimer's disease. Neurobiol. Aging 8, 521-545. doi: 10.1016/0197-4580(87)90127-8

Cooke, M. S., Evans, M. D., Dizdaroglu, M., and Lunec, J. (2003). Oxidative DNA damage: mechanisms, mutation and disease. FASEB J. 17, 1195-1214. doi: 10.1096/fj.02-0752rev

Costantini, C., Lorenzetto, E., Cellini, B., Buffelli, M., Rossi, F., and DellaBianca, V. (2010). Astrocytes regulate the expression of insulin-like growth factor 1 receptor (IGF1-R) in primary cortical neurons during in vitro senescence. J. Mol. Neurosci. 40, 342-352. doi: 10.1007/s12031-0099305-5

Cragg, B. G. (1975). The density of synapses and neurons in normal, mentally defective ageing human brains. Brain 98, 81-90. doi: 10.1093/brain/98.1.81

Curtis, A. M., Fagundes, C. T., Yang, G., Palsson-McDermott, E. M., Wochal, P., McGettrick, A. F., et al. (2015). Circadian control of innate immunity in macrophages by miR-155 targeting Bmal1. Proc. Natl. Acad. Sci. U S A 112, 7231-7236. doi: 10.1073/pnas.1501327112

Das, M. M., Avalos, P., Suezaki, P., Godoy, M., Garcia, L., Chang, C. D., et al. (2016). Human neural progenitors differentiate into astrocytes and protect motor neurons in aging rats. Exp. Neurol. 280, 41-49. doi: 10.1016/j.expneurol. 2016.03.023

Das, M. M., and Svendsen, C. N. (2015). Astrocytes show reduced support of motor neurons with aging that is accelerated in a rodent model of ALS. Neurobiol. Aging 36, 1130-1139. doi: 10.1016/j.neurobiolaging.2014.09.020

Diniz, D. G., de Oliveira, M. A., de Lima, C. M., Fôro, C. A., Sosthenes, M. C., Bento-Torres, J., et al. (2016). Age, environment, object recognition and morphological diversity of GFAP-immunolabeled astrocytes. Behav. Brain Funct. 12:28. doi: 10.1186/s12993-016-0111-2

Dizdaroglu, M., Jaruga, P., Birincioglu, M., and Rodriguez, H. (2002). Free radicalinduced damage to DNA: mechanisms and measurement. Free Radic. Biol. Med. 32, 1102-1115. doi: 10.1016/S0891-5849(02)00826-2

Doucette, J. R., Jiao, R., and Nazarali, A. J. (2010). Age-related and cuprizoneinduced changes in myelin and transcription factor gene expression and in oligodendrocyte cell densities in the rostral corpus callosum of mice. Cell. Mol. Neurobiol. 30, 607-629. doi: 10.1007/s10571-009-9486-Z

Driscoll, I., Davatzikos, C., An, Y., Wu, X., Shen, D., Kraut, M., et al. (2009). Longitudinal pattern of regional brain volume change differentiates normal aging from MCI. Neurology 72, 1906-1913. doi: 10.1212/wnl. 0b013e3181a82634

Duhart, J. M., Leone, M. J., Paladino, N., Evans, J. A., Castanon-Cervantes, O., Davidson, A. J., et al. (2013). Suprachiasmatic astrocytes modulate the circadian clock in response to TNF- $\alpha$. J. Immunol. 191, 4656-4664. doi: 10.4049/jimmunol.1300450
Evans, M. D., Dizdaroglu, M., and Cooke, M. S. (2004). Oxidative DNA damage and disease: induction, repair and significance. Mutat. Res. 567, 1-61. doi: 10.1016/j.mrrev.2003.11.001

Fabricius, K., Jacobsen, J. S., and Pakkenberg, B. (2013). Effect of age on neocortical brain cells in $90+$ year old human females-a cell counting study. Neurobiol. Aging 34, 91-99. doi: 10.1016/j.neurobiolaging.2012.06.009

Farrall, A. J., and Wardlaw, J. M. (2009). Blood-brain barrier: ageing and microvascular disease-systematic review and meta-analysis. Neurobiol. Aging 30, 337-352. doi: 10.1016/j.neurobiolaging.2007.07.015

Fearnley, J. M., and Lees, A. J. (1991). Ageing and Parkinson's disease: substantia nigra regional selectivity. Brain 114, 2283-2301. doi: 10.1093/brain/114. 5.2283

Ferris, H. A., Perry, R. J., Moreira, G. V., Shulman, G. I., Horton, J. D., and Kahn, C. R. (2017). Loss of astrocyte cholesterol synthesis disrupts neuronal function and alters whole-body metabolism. Proc. Natl. Acad. Sci. U S A 114, 1189-1194. doi: 10.1073/pnas.1620506114

Fjell, A. M., Walhovd, K. B., Fennema-Notestine, C., McEvoy, L. K., Hagler, D. J., Holland, D., et al. (2009). One-year brain atrophy evident in healthy aging. J. Neurosci. 29, 15223-15231. doi: 10.1523/jneurosci.325209.2009

Franceschi, C., Capri, M., Monti, D., Giunta, S., Olivieri, F., Sevini, F., et al. (2007). Inflammaging and anti-inflammaging: a systemic perspective on aging and longevity emerged from studies in humans. Mech. Ageing Dev. 128, 92-105. doi: 10.1016/j.mad.2006.11.016

Freeman, S. H., Kandel, R., Cruz, L., Rozkalne, A., Newell, K., Frosch, M. P., et al. (2008). Preservation of neuronal number despite age-related cortical brain atrophy in elderly subjects without Alzheimer disease. J. Neuropathol. Exp. Neurol. 67, 1205-1212. doi: 10.1097/NEN.0b013e3181 $8 \mathrm{fc} 72 \mathrm{f}$

Ge, Y., Grossman, R. I., Babb, J. S., Rabin, M. L., Mannon, L. J., and Kolson, D. L. (2002). Age-related total gray matter and white matter changes in normal adult brain. Part I: volumetric MR imaging analysis. AJNR Am. J. Neuroradiol. 23, 1327-1333.

Golombek, D. A., and Rosenstein, R. E. (2010). Physiology of circadian entrainment. Physiol. Rev. 90, 1063-1102. doi: 10.1152/physrev.00009.2009

Goodall, E. F., Wang, C., Simpson, J. E., Baker, D. J., Drew, D. R., Heath, P. R., et al. (2018). Age-associated changes in the blood-brain barrier: comparative studies in human and mouse. Neuropathol. Appl. Neurobiol. 44, 328-340. doi: $10.1111 /$ nan. 12408

Grabert, K., Michoel, T., Karavolos, M. H., Clohisey, S., Baillie, J. K., Stevens, M. P., et al. (2016). Microglial brain region-dependent diversity and selective regional sensitivities to aging. Nat. Neurosci. 19, 504-516. doi: 10.1038/nn.4222

Grimm, S., Hoehn, A., Davies, K. J., and Grune, T. (2011). Protein oxidative modifications in the ageing brain: consequence for the onset of neurodegenerative disease. Free Radic. Res. 45, 73-88. doi: 10.3109/10715762. 2010.512040

Hafezi-Moghadam, A., Thomas, K. L., and Wagner, D. D. (2007). ApoE deficiency leads to a progressive age-dependent blood-brain barrier leakage. Am. J. Physiol. Cell Physiol. 292, C1256-C1262. doi: 10.1152/ajpcell.00563.2005

Haider, L., Fischer, M. T., Frischer, J. M., Bauer, J., Hoftberger, R., Botond, G., et al. (2011). Oxidative damage in multiple sclerosis lesions. Brain 134, 1914-1924. doi: 10.1093/brain/awr128

Haidet-Phillips, A. M., Hester, M. E., Miranda, C. J., Meyer, K., Braun, L., Frakes, A., et al. (2011). Astrocytes from familial and sporadic ALS patients are toxic to motor neurons. Nat. Biotechnol. 29, 824-828. doi: 10.1038/nbt.1957

Hammad, A., Westacott, L., and Zaben, M. (2018). The role of the complement system in traumatic brain injury: a review. J. Neuroinflammation 15:24. doi: 10.1186/s12974-018-1097-5

Hansen, L. A., Armstrong, D. M., and Terry, R. D. (1987). An immunohistochemical quantification of fibrous astrocytes in the aging human cerebral cortex. Neurobiol. Aging 8, 1-6. doi: 10.1016/0197-4580(87) 90051-0

Hatada, I., Namihira, M., Morita, S., Kimura, M., Horii, T., and Nakashima, K. (2008). Astrocyte-specific genes are generally demethylated in neural precursor cells prior to astrocytic differentiation. PLoS One 3:e3189. doi: 10.1371/journal. pone.0003189

He, W., Goodkind, D., and Kowal, P. (2016). An Aging World: 2015 International Population Reports. Washington, DC: Census Bureau. 
Hickman, S. E., Kingery, N. D., Ohsumi, T. K., Borowsky, M. L., Wang, L. C., Means, T. K., et al. (2013). The microglial sensome revealed by direct RNA sequencing. Nat. Neurosci. 16, 1896-1905. doi: 10.1038/nn.3554

Hood, S., and Amir, S. (2017). The aging clock: circadian rhythms and later life. J. Clin. Invest. 127, 437-446. doi: 10.1172/JCI90328

Hosokawa, M., and Ueno, M. (1999). Aging of blood-brain barrier and neuronal cells of eye and ear in SAM mice. Neurobiol. Aging 20, 117-123. doi: 10.1016/s0197-4580(99)00029-9

Hou, L., Liu, Y., Wang, X., Ma, H., He, J., Zhang, Y., et al. (2011). The effects of amyloid- $\beta 42$ oligomer on the proliferation and activation of astrocytes in vitro. in vitro Cell. Dev. Biol. Anim. 47, 573-580. doi: 10.1007/s11626-0119439-y

Howcroft, T. K., Campisi, J., Louis, G. B., Smith, M. T., Wise, B., Wyss-Coray, T., et al. (2013). The role of inflammation in age-related disease. Aging 5, 84-93. doi: 10.18632/aging.100531

Hung, C.-W., Chen, Y.-C., Hsieh, W.-L., Chiou, S.-H., and Kao, C.-L. (2010). Ageing and neurodegenerative diseases. Ageing Res. Rev. 9, S36-S46. doi: 10.1016/j.arr.2010.08.006

Ishii, T., Takanashi, Y., Sugita, K., Miyazawa, M., Yanagihara, R., Yasuda, K., et al. (2017). Endogenous reactive oxygen species cause astrocyte defects and neuronal dysfunctions in the hippocampus: a new model for aging brain. Aging Cell 16, 39-51. doi: 10.1111/acel.12523

Issa, J. P. (2014). Aging and epigenetic drift: a vicious cycle. J. Clin. Invest. 124, 24-29. doi: 10.1172/jci69735

Jinno, S. (2011). Regional and laminar differences in antigen profiles and spatial distributions of astrocytes in the mouse hippocampus, with reference to aging. Neuroscience 180, 41-52. doi: 10.1016/j.neuroscience.2011.02.013

Jones, A., Kumar, S., Zhang, N., Tong, Z., Yang, J. H., Watt, C., et al. (2011). Increased expression of multifunctional serine protease, HTRA1, in retinal pigment epithelium induces polypoidal choroidal vasculopathy in mice. Proc. Natl. Acad. Sci. U S A 108, 14578-14583. doi: 10.1073/pnas.11028 53108

Jyothi, H. J., Vidyadhara, D. J., Mahadevan, A., Philip, M., Parmar, S. K., Manohari, S. G., et al. (2015). Aging causes morphological alterations in astrocytes and microglia in human substantia nigra pars compacta. Neurobiol. Aging 36, 3321-3333. doi: 10.1016/j.neurobiolaging.2015.08.024

Kanaan, N. M., Kordower, J. H., and Collier, T. J. (2010). Age-related changes in glial cells of dopamine midbrain subregions in rhesus monkeys. Neurobiol. Aging 31, 937-952. doi: 10.1016/j.neurobiolaging.2008.07.006

Kasperczyk, H., Baumann, B., Debatin, K. M., and Fulda, S. (2009). Characterization of sonic hedgehog as a novel NF-kB target gene that promotes NF-кB-mediated apoptosis resistance and tumor growth in vivo. FASEB J. 23, 21-33. doi: 10.1096/fj.08-111096

Kirk, J., Plumb, J., Mirakhur, M., and McQuaid, S. (2003). Tight junctional abnormality in multiple sclerosis white matter affects all calibres of vessel and is associated with blood-brain barrier leakage and active demyelination. J. Pathol. 201, 319-327. doi: 10.1002/path.1434

Kohama, S. G., Goss, J. R., Finch, C. E., and McNeill, T. H. (1995). Increases of glial fibrillary acidic protein in the aging female mouse brain. Neurobiol. Aging 16, 59-67. doi: 10.1016/0197-4580(95)80008-f

Kondratova, A. A., and Kondratov, R. V. (2012). The circadian clock and pathology of the ageing brain. Nat. Rev. Neurosci. 13, 325-335. doi: $10.1038 / \mathrm{nrn} 3208$

Kraft, A. D., Johnson, D. A., and Johnson, J. A. (2004). Nuclear factor E2-related factor 2-dependent antioxidant response element activation by tert-butylhydroquinone and sulforaphane occurring preferentially in astrocytes conditions neurons against oxidative insult. J. Neurosci. 24, 1101-1112. doi: 10.1523/jneurosci.3817-03.2004

Krishnan, N., Rakshit, K., Chow, E. S., Wentzell, J. S., Kretzschmar, D., and Giebultowicz, J. M. (2012). Loss of circadian clock accelerates aging in neurodegeneration-prone mutants. Neurobiol. Dis. 45, 1129-1135. doi: 10.1016/j.nbd.2011.12.034

Kudin, A. P., Malinska, D., and Kunz, W. S. (2008). Sites of generation of reactive oxygen species in homogenates of brain tissue determined with the use of respiratory substrates and inhibitors. Biochim. Biophys. Acta 1777, 689-695. doi: 10.1016/j.bbabio.2008.05.010

Lalo, U., Rasooli-Nejad, S., and Pankratov, Y. (2014). Exocytosis of gliotransmitters from cortical astrocytes: implications for synaptic plasticity and aging. Biochem. Soc. Trans. 42, 1275-1281. doi: 10.1042/bst201 40163

Lamberti, C., Lin, K. M., Yamamoto, Y., Verma, U., Verma, I. M., Byers, S., et al. (2001). Regulation of $\beta$-catenin function by the IкB kinases. J. Biol. Chem. 276, 42276-42286. doi: 10.1074/jbc.M104227200

Lananna, B. V., Collin, J. N., Izumo, M., Cedeño, M. R., Xiong, D. D., Dimitry, J., et al. (2018). Cell-autonomous regulation of astrocyte activation by the circadian clock protein BMAL1. Cell Rep. 25, 1.e5-9.e5. doi: 10.1101/362814

Lassmann, H., and van Horssen, J. (2016). Oxidative stress and its impact on neurons and glia in multiple sclerosis lesions. Biochim. Biophys. Acta 1862, 506-510. doi: 10.1016/j.bbadis.2015.09.018

Lazarczyk, M. J., Kemmler, J. E., Eyford, B. A., Short, J. A., Varghese, M., Sowa, A., et al. (2016). Major histocompatibility complex class I proteins are critical for maintaining neuronal structural complexity in the aging brain. Sci. Rep. 6:26199. doi: 10.1038/srep26199

Lei, M., Hua, X., Xiao, M., Ding, J., Han, Q., and Hu, G. (2008). Impairments of astrocytes are involved in the d-galactose-induced brain aging. Biochem. Biophys. Res. Commun. 369, 1082-1087. doi: 10.1016/j.bbrc.2008.02.151

Li, X., Pu, F., Fan, Y., Niu, H., Li, S., and Li, D. (2013). Age-related changes in brain structural covariance networks. Front. Hum. Neurosci. 7:98. doi: 10.3389/fnhum.2013.00098

Lian, H., Litvinchuk, A., Chiang, A. C., Aithmitti, N., Jankowsky, J. L., and Zheng, H. (2016). Astrocyte-microglia cross talk through complement activation modulates amyloid pathology in mouse models of Alzheimer's disease. J. Neurosci. 36, 577-589. doi: 10.1523/jneurosci.2117-1 5.2016

Lian, H., Yang, L., Cole, A., Sun, L., Chiang, A. C., Fowler, S. W., et al. (2015). NFKB-activated astroglial release of complement C3 compromises neuronal morphology and function associated with Alzheimer's disease. Neuron 85, 101-115. doi: 10.3389/fimmu.2015.00220

Licht-Mayer, S., Wimmer, I., Traffehn, S., Metz, I., Bruck, W., Bauer, J., et al. (2015). Cell type-specific Nrf2 expression in multiple sclerosis lesions. Acta Neuropathol. 130, 263-277. doi: 10.1007/s00401-015-1452-x

Liddelow, S. A., Guttenplan, K. A., Clarke, L. E., Bennett, F. C., Bohlen, C. J., Schirmer, L., et al. (2017). Neurotoxic reactive astrocytes are induced by activated microglia. Nature 541, 481-487. doi: 10.1038/nature21029

Liguori, I., Russo, G., Curcio, F., Bulli, G., Aran, L., Della-Morte, D., et al. (2018). Oxidative stress, aging and diseases. Clin. Interv. Aging 13, 757-772. doi: $10.2147 /$ CIA.S158513

Lin, D.-T., Wu, J., Holstein, D., Upadhyay, G., Rourk, W., Muller, E., et al. (2007). $\mathrm{Ca}^{+}$signaling, mitochondria and sensitivity to oxidative stress in aging astrocytes. Neurobiol. Aging 28, 99-111. doi: 10.1016/j.neurobiolaging. 2005.11.004

Lindsey, J. D., Landfield, P. W., and Lynch, G. (1979). Early onset and topographical distribution of hypertrophied astrocytes in hippocampus of aging rats: a quantitative study. J. Gerontol. 34, 661-671. doi: 10.1093/geronj/34. 5.661

Liu, L., Cheung, T. H., Charville, G. W., Hurgo, B. M., Leavitt, T., Shih, J., et al. (2013). Chromatin modifications as determinants of muscle stem cell quiescence and chronological aging. Cell Rep. 4, 189-204. doi: 10.1016/j.celrep. 2013.05.043

Logroscino, G., Tortelli, R., Rizzo, G., Marin, B., Preux, P. M., and Malaspina, A. (2015). Amyotrophic lateral sclerosis: an aging-related disease. Curr. Geriat. Rep. 4, 142-153. doi: 10.1007/S13670-015-0127-8

Lowrey, P. L., and Takahashi, J. S. (2011). Genetics of circadian rhythms in Mammalian model organisms. Adv. Genet. 74, 175-230. doi: 10.1016/b978-012-387690-4.00006-4

Lu, L., Li, J., Yew, D. T., Rudd, J. A., and Mak, Y. T. (2008). Oxidative stress on the astrocytes in culture derived from a senescence accelerated mouse strain. Neurochem. Int. 52, 282-289. doi: 10.1016/j.neuint.2007.06.016

Lukiw, W. J., Bjattacharjee, S., Zhao, Y., Pogue, A. I., and Percy, M. E. (2012). Generation of reactive oxygen species (ROS) and pro-inflammatory signaling in human brain cells in primary culture. J. Alzheimers Dis. Parkinsonism 2:001. doi: 10.4172/2161-0460.s2-001

Ma, S. Y., Röytt, M., Collan, Y., and Rinne, J. O. (1999). Unbiased morphometrical measurements show loss of pigmented nigral neurones with ageing. Neuropathol. Appl. Neurobiol. 25, 394-399. doi: 10.1046/j.1365-2990. 1999.00202.x 
Mackic, J. B., Bading, J., Ghiso, J., Walker, L., Wisniewski, T., Frangione, B., et al. (2002). Circulating amyloid- $\beta$ peptide crosses the blood-brain barrier in aged monkeys and contributes to Alzheimer's disease lesions. Vascul. Pharmacol. 38, 303-313. doi: 10.1016/s1537-1891(02)00198-2

Madison, B. B. (2016). Srebp2: a master regulator of sterol and fatty acid synthesis. J. Lipid Res. 57, 333-335. doi: 10.1194/jlr.c066712

Maegawa, S., Hinkal, G., Kim, H. S., Shen, L., Zhang, L., Zhang, J., et al. (2010). Widespread and tissue specific age-related DNA methylation changes in mice. Genome Res. 20, 332-340. doi: 10.1101/gr.096826.109

Mangold, C. A., Masser, D. R., Stanford, D. R., Bixler, G. V., Pisupati, A., Giles, C. B., et al. (2017). CNS-wide sexually dimorphic induction of the major histocompatibility complex 1 pathway with aging. J. Gerontol. A Biol. Sci. Med. Sci. 72, 16-29. doi: 10.1093/gerona/glv232

Mansour, H., Chamberlain, C. G., Weible, M. W., Hughes, S., Chu, Y., and ChanLing, T. (2008). Aging-related changes in astrocytes in the rat retina: imbalance between cell proliferation and cell death reduces astrocyte availability. Aging Cell 7, 526-540. doi: 10.1111/j.1474-9726.2008.00402.x

Marin, B., Hamidou, B., Couratier, P., Nicol, M., Delzor, A., Raymondeau, M., et al. (2014). Population-based epidemiology of amyotrophic lateral sclerosis (ALS) in an ageing Europe - the French register of ALS in Limousin (FRALim register). Eur. J. Neurol. 21, 1292-1300, e78-e79. doi: 10.1111/ene.12474

Markiewski, M. M., and Lambris, J. D. (2007). The role of complement in inflammatory diseases from behind the scenes into the spotlight. Am. J. Pathol. 171, 715-727. doi: 10.2353/ajpath.2007.070166

Marner, L., Nyengaard, J. R., Tang, Y., and Pakkenberg, B. (2003). Marked loss of myelinated nerve fibers in the human brain with age. J. Comp. Neurol. 462, 144-152. doi: 10.1002/cne.10714

Mattis, J., and Sehgal, A. (2016). Circadian rhythms, sleep, and disorders of aging. Trends Endocrinol. Metab. 27, 192-203. doi: 10.1016/j.tem.2016.02.003

Mayford, M., Siegelbaum, S. A., and Kandel, E. R. (2012). Synapses and memory storage. Cold Spring Harb. Perspect. Biol. 4:a005751. doi: 10.1101/cshperspect. a005751

Miguel-Hidalgo, J. J. (2018). Molecular neuropathology of astrocytes and oligodendrocytes in alcohol use disorders. Front. Mol. Neurosci. 11:78. doi: 10.3389/fnmol.2018.00078

Monteiro de Castro, G., Deja, N. A., Ma, D., Zhao, C., and Franklin, R. J. (2015). Astrocyte activation via stat 3 signaling determines the balance of oligodendrocyte versus schwann cell remyelination. Am. J. Pathol. 185, 2431-2440. doi: 10.1016/j.ajpath.2015.05.011

Mooradian, A. D., and McCuskey, R. S. (1992). In vivo microscopic studies of age-related changes in the structure and the reactivity of cerebral microvessels. Mech. Ageing Dev. 64, 247-254. doi: 10.1016/0047-6374(92)90082-o

Morrisette-Thomas, V., Cohen, A. A., Fülöp, T., Riesco, É., Legault, V., Li, Q., et al. (2014). Inflamm-aging does not simply reflect increases in pro-inflammatory markers. Mech. Ageing Dev. 139, 49-57. doi: 10.1016/j.mad.2014. 06.005

Mu, S. H., Xu, M., Duan, J. X., Zhang, J., and Tan, L. H. (2017). Localizing age-related changes in brain structure using voxel-based morphometry. Neural Plast. 2017:6303512. doi: 10.1155/2017/6303512

Nag, T. C., and Wadhwa, S. (2012). Accumulation of lipid inclusions in astrocytes of aging human optic nerve. Acta Biol. Hung. 63, 54-64. doi: 10.1556/abiol.63. 2012.suppl.1.6

Nagy, C., Suderman, M., Yang, J., Szyf, M., Mechawar, N., Ernst, C., et al. (2015). Astrocytic abnormalities and global DNA methylation patterns in depression and suicide. Mol. Psychiatry 20, 320-328. doi: 10.1038/mp.2014.21

Namihira, M., Kohyama, J., Semi, K., Sanosaka, T., Deneen, B., Taga, T., et al. (2009). Committed neuronal precursors confer astrocytic potential on residual neural precursor cells. Dev. Cell 16, 245-255. doi: 10.1016/j.devcel.2008.12.014

Namihira, M., Nakashima, K., and Taga, T. (2004). Developmental stage dependent regulation of DNA methylation and chromatin modification in a immature astrocyte specific gene promoter. FEBS Lett. 572, 184-188. doi: 10.1016/j.febslet.2004.07.029

Nedergaard, M., Ransom, B., and Goldman, S. A. (2003). New roles for astrocytes: redefining the functional architecture of the brain. Trends Neurosci. 26, 523-530. doi: 10.1016/j.tins.2003.08.008

Niccoli, T., Partridge, L., and Isaacs, A. M. (2017). Ageing as a risk factor for ALS/FTD. Hum. Mol. Genet. 26, R105-R113. doi: 10.1093/hmg/ ddx 247
Nichols, N. R., Day, J. R., Laping, N. J., Johnson, S. A., and Finch, C. E. (1993). GFAP mRNA increases with age in rat and human brain. Neurobiol. Aging 14, 421-429. doi: 10.1016/0197-4580(93)90100-p

Nijland, P. G., Witte, M. E., van het Hof, B., van der Pol, S., Bauer, J., Lassmann, H., et al. (2014). Astroglial PGC- $1 \alpha$ increases mitochondrial antioxidant capacity and suppresses inflammation: implications for multiple sclerosis. Acta Neuropathol. Commun. 2:170. doi: 10.1186/s40478-014-0170-2

Nobuta, H., Ghiani, C. A., Paez, P. M., Spreuer, V., Dong, H., Korsak, R. A., et al. (2012). STAT3-mediated astrogliosis protects myelin development in neonatal brain injury. Ann. Neurol. 72, 750-765. doi: 10.1002/ana.23670

Norden, D. M., Fenn, A. M., Dugan, A., and Godbout, J. P. (2014). TGF $\beta$ produced by IL-10 redirected astrocytes attenuates microglial activation. Glia 62, 881-895. doi: 10.1002/glia.22647

Norden, D. M., and Godbout, J. P. (2013). Review: microglia of the aged brain: primed to be activated and resistant to regulation. Neuropathol. Appl. Neurobiol. 39, 19-34. doi: 10.1111/j.1365-2990.2012.01306.x

Nuutinen, T., Suuronen, T., Kauppinen, A., and Salminen, A. (2010). Valproic acid stimulates clusterin expression in human astrocytes: implications for Alzheimer's disease. Neurosci. Lett. 475, 64-68. doi: 10.1016/j.neulet.2010. 03.041

Oberheim, N. A., Takano, T., Han, X., He, W., Lin, J. H., Wang, F., et al. (2009). Uniquely hominid features of adult human astrocytes. J. Neurosci. 29, 3276-3287. doi: 10.1523/JNEUROSCI.4707-08.2009

Omari, K. M., John, G. R., Sealfon, S. C., and Raine, C. S. (2005). CXC chemokine receptors on human oligodendrocytes: implications for multiple sclerosis. Brain 128, 1003-1015. doi: 10.1093/brain/awh479

Orre, M., Kamphuis, W., Osborn, L. M., Melief, J., Kooijman, L., Huitinga, I., et al. (2014). Acute isolation and transcriptome characterization of cortical astrocytes and microglia from young and aged mice. Neurobiol. Aging 35, 1-14. doi: 10.1016/j.neurobiolaging.2013.07.008

Osipova, E. D., Komleva, Y. K., Morgun, A. V., Lopatina, O. L., Panina, Y. A., Olovyannikova, R. Y., et al. (2018). Designing in vitro blood-brain barrier models reproducing alterations in brain aging. Front. Aging Neurosci. 10:234. doi: 10.3389/fnagi.2018.00234

Paczek, L., Michalska, W., and Bartlomiejczyk, I. (2009). Proteolytic enzyme activity as a result of aging. Aging Clin. Exp. Res. 21, 9-13. doi: 10.1007/bf03324892

Pannese, E. (2011). Morphological changes in nerve cells during normal aging. Brain Struct. Funct. 216, 85-89. doi: 10.1007/s00429-011-0308-y

Pelvig, D. P., Pakkenberg, H., Stark, A. K., and Pakkenberg, B. (2008). Neocortical glial cell numbers in human brains. Neurobiol. Aging 29, 1754-1762. doi: 10.1016/j.neurobiolaging.2007.04.013

Popescu, B. O., Toescu, E. C., Popescu, L. M., Bajenaru, O., Muresanu, D. F., Schultzberg, M., et al. (2009). Blood-brain barrier alterations in ageing and dementia. J. Neurol. Sci. 283, 99-106. doi: 10.1016/j.jns.2009.02.321

Querfurth, H. W., and LaFerla, F. M. (2010). Alzheimer's disease. N. Engl. J. Med. 362, 329-344. doi: 10.1056/NEJMra0909142

Raz, N., Lindenberger, U., Rodrigue, K. M., Kennedy, K. M., Head, D., Williamson, A., et al. (2005). Regional brain changes in aging healthy adults: general trends, individual differences and modifiers. Cereb. Cortex 15, 1676-1689. doi: 10.1093/cercor/bhi044

Re, D. B., Le Verche, V., Yu, C., Amoroso, M. W., Politi, K. A., Phani, S., et al. (2014). Necroptosis drives motor neuron death in models of both sporadic and familial ALS. Neuron 81, 1001-1008. doi: 10.1016/j.neuron.2014. 01.011

Rea, I. M., Gibson, D. S., McGilligan, V., McNerlan, S. E., Alexander, H. D., and Ross, O. A. (2018). Age and age-related diseases: role of inflammation triggers and cytokines. Front. Immunol. 9:586. doi: 10.3389/fimmu.2018.00586

Reeve, A., Simcox, E., and Turnbull, D. (2014). Ageing and Parkinson's disease: why is advancing age the biggest risk factor? Ageing Res. Rev. 14, 19-30. doi: 10.1016/j.arr.2014.01.004

Resnick, S. M., Pham, D. L., Kraut, M. A., Zonderman, A. B., and Davatzikos, C. (2003). Longitudinal magnetic resonance imaging studies of older adults: a shrinking brain. J. Neurosci. 23, 3295-3301. doi: 10.1523/JNEUROSCI.23-0803295.2003

Robillard, K. N., Lee, K. M., Chiu, K. B., and MacLean, A. G. (2016). Glial cell morphological and density changes through the lifespan of rhesus macaques. Brain Behav. Immun. 55, 60-69. doi: 10.1016/j.bbi.2016.01.006 
Rodriguez, M., Rodriguez-Sabate, C., Morales, I., Sanchez, A., and Sabate, M. (2015). Parkinson's disease as a result of aging. Aging Cell 14, 293-308. doi: $10.1111 /$ acel.12312

Rothhammer, V., Borucki, D. M., Tjon, E. C., Takenaka, M. C., Chao, C. C., Ardura-Fabregat, A., et al. (2018). Microglial control of astrocytes in response to microbial metabolites. Nature 557, 724-728. doi: 10.1038/s41586-0180119-x

Rowland, L. P., and Shneider, N. A. (2001). Amyotrophic lateral sclerosis. N. Engl. J. Med. 344, 1688-1700. doi: 10.1056/NEJM200105313442207

Rozovsky, I., Finch, C. E., and Morgan, T. E. (1998). Age-related activation of microglia and astrocytes: in vitro studies show persistent phenotypes of aging, increased proliferation and resistance to down-regulation. Neurobiol. Aging 19, 97-103. doi: 10.1016/s0197-4580(97)00169-3

Rudow, G., O’Brien, R., Savonenko, A. V., Resnick, S. M., Zonderman, A. B., Pletnikova, O., et al. (2008). Morphometry of the human substantia nigra in ageing and Parkinson's disease. Acta Neuropathol. 115, 461-470. doi: 10.1007/s00401-008-0352-8

Safavi, F., and Rostami, A. (2012). Role of serine proteases in inflammation: bowman-birk protease inhibitor (BBI) as a potential therapy for autoimmune diseases. Exp. Mol. Pathol. 93, 428-433. doi: 10.1016/j.yexmp.2012.09.014

Scahill, R. I., Frost, C., Jenkins, R., Whitwell, J. L., Rossor, M. N., and Fox, N. C. (2003). A longitudinal study of brain volume changes in normal aging using serial registered magnetic resonance imaging. Arch. Neurol. 60, 989-994. doi: 10.1001/archneur.60.7.989

Shi, Z. M., Han, Y. W., Han, X. H., Zhang, K., Chang, Y. N., Hu, Z. M., et al. (2016). Upstream regulators and downstream effectors of NF- $\kappa B$ in Alzheimer's disease. J. Neurol. Sci. 366, 127-134. doi: 10.1016/j.jns.2016.05.022

Shih, A. Y., Johnson, D. A., Wong, G., Kraft, A. D., Jiang, L., Erb, H., et al. (2003). Coordinate regulation of glutathione biosynthesis and release by Nrf2-expressing glia potently protects neurons from oxidative stress. J. Neurosci. 23, 3394-3406. doi: 10.1523/JNEUROSCI.23-08-03394.2003

Sofroniew, M. V. (2014). Astrogliosis. Cold Spring Harb. Perspect. Biol. 7:a020420. doi: 10.1101/cshperspect.a020420

Sofroniew, M. V., and Vinters, H. V. (2010). Astrocytes: biology and pathology. Acta Neuropathol. 119, 7-35. doi: 10.1007/s00401-009-0619-8

Sorensen, E. W., Lian, J., Ozga, A. J., Miyabe, Y., Ji, S. W., Bromley, S. K., et al. (2018). CXCL10 stabilizes T cell-brain endothelial cell adhesion leading to the induction of cerebral malaria. JCI Insight 3:98911. doi: 10.1172/jci.insight. 98911

Soreq, L., UK Brain Expression Consortium, North American Brain Expression Consortium, Rose, J., Soreq, E., Hardy, J., et al. (2017). Major shifts in glial regional identity are a transcriptional hallmark of human brain aging. Cell Rep. 18, 557-570. doi: 10.1016/j.celrep.2016.12.011

Stamatovic, S. M., Keep, R. F., and Andjelkovic, A. V. (2008). Brain endothelial cell-cell junctions: how to "open" the blood brain barrier. Curr. Neuropharmacol. 6, 179-192. doi: 10.2174/157015908785777210

Staszewski, O., and Prinz, M. (2014). Glial epigenetics in neuroinflammation and neurodegeneration. Cell Tissue Res. 356, 609-616. doi: 10.1007/s00441-0141815-y

Stephan, A. H., Barres, B. A., and Stevens, B. (2012). The complement system: an unexpected role in synaptic pruning during development and disease. Annu. Rev. Neurosci. 35, 369-389. doi: 10.1146/annurev-neuro-061010-113810

Stevens, B., Allen, N. J., Vazquez, L. E., Howell, G. R., Christopherson, K. S., Nouri, N., et al. (2007). The classical complement cascade mediates CNS synapse elimination. Cell 131, 1164-1178. doi: 10.1016/j.cell.2007.10.036

Straif, K., Baan, R., Grosse, Y., Secretan, B., El Ghissassi, F., Bouvard, V., et al. (2007). Carcinogenicity of shift-work, painting and fire-fighting. Lancet Oncol. 8, 1065-1066. doi: 10.1016/s1470-2045(07)70373-x

Sturrock, R. R. (1989). Age related changes in neuron number in the mouse lateral vestibular nucleus. J. Anat. 166, 227-232.

Sundar Boyalla, S., Barbara Victor, M., Roemgens, A., Beyer, C., and Arnold, S. (2011). Sex- and brain region-specific role of cytochrome $c$ oxidase in 1methyl-4-phenylpyridinium-mediated astrocyte vulnerability. J. Neurosci. Res. 89, 2068-2082. doi: 10.1002/jnr.22669

Swain, U., and Subba Rao, K. (2011). Study of DNA damage via the comet assay and base excision repair activities in rat brain neurons and astrocytes during aging. Mech. Ageing Dev. 132, 374-381. doi: 10.1016/j.mad.2011.04.012

Takouda, J., Katada, S., and Nakashima, K. (2017). Emerging mechanisms underlying astrogenesis in the developing mammalian brain. Proc.
Jpn. Acad. Ser. B Phys. Biol. Sci. 93, 386-398. doi: 10.2183/pjab. 93.024

Terry, R. D., DeTeresa, R., and Hansen, L. A. (1987). Neocortical cell counts in normal human adult aging. Ann. Neurol. 21, 530-539. doi: 10.1002/ana. 410210603

Tse, K. H., and Herrup, K. (2017). DNA damage in the oligodendrocyte lineage and its role in brain aging. Mech. Ageing Dev. 161, 37-50. doi: 10.1016/j.mad. 2016.05.006

Tso, C. F., Simon, T., Greenlaw, A. C., Puri, T., Mieda, M., and Herzog, E. D. (2017). Astrocytes regulate daily rhythms in the suprachiasmatic nucleus and behavior. Curr. Biol. 27, 1055-1061. doi: 10.1016/j.cub.2017.02.037

van Deijk, A. F., Camargo, N., Timmerman, J., Heistek, T., Brouwers, J. F., Mogavero, F., et al. (2017). Astrocyte lipid metabolism is critical for synapse development and function in vivo. Glia 65, 670-682. doi: 10.1002/glia.23120

van Horssen, J., Drexhage, J. A., Flor, T., Gerritsen, W., van der Valk, P., and de Vries, H. E. (2010). Nrf2 and DJ1 are consistently upregulated in inflammatory multiple sclerosis lesions. Free Radic. Biol. Med. 49, 1283-1289. doi: 10.1016/j. freeradbiomed.2010.07.013

van Horssen, J., Schreibelt, G., Drexhage, J., Hazes, T., Dijkstra, C. D., van der Valk, P., et al. (2008). Severe oxidative damage in multiple sclerosis lesions coincides with enhanced antioxidant enzyme expression. Free Radic. Biol. Med. 45, 1729-1737. doi: 10.1016/j.freeradbiomed.2008.09.023

Vorbrodt, A. W., and Dobrogowska, D. H. (1994). Immunocytochemical evaluation of blood-brain barrier to endogenous albumin in adult, newborn and aged mice. Folia Histochem. Cytobiol. 32, 63-70.

Wadhwani, K. C., Koistinaho, J., Balbo, A., and Rapoport, S. I. (1991). Blood-nerve and blood-brain barrier permeabilities and nerve vascular space in Fischer-344 rats of different ages. Mech. Ageing Dev. 58, 177-190. doi: 10.1016/00476374(91)90091-d

Wang, X., Xu, Y., Wang, F., Tang, L., Liu, Z., Li, H., et al. (2006). Aging-related changes of microglia and astrocytes in hypothalamus after intraperitoneal injection of hypertonic saline in rats. J. Huazhong Univ. Sci. Technol. Med. Sci. 26, 231-234. doi: 10.1007/bf02895824

Wang, H.-M., Zhang, T., Huang, J.-K., and Sun, X.-J. (2013). 3-N-butylphthalide (NBP) attenuates the amyloid- $\beta$-induced inflammatory responses in cultured astrocytes via the nuclear factor-кB signaling pathway. Cell. Physiol. Biochem. 32, 235-242. doi: 10.1159/000350139

Wood, J. G., Hillenmeyer, S., Lawrence, C., Chang, C., Hosier, S., Lightfoot, W., et al. (2010). Chromatin remodeling in the aging genome of Drosophila. Aging Cell 9, 971-978. doi: 10.1111/j.1474-9726.2010.00624.x

Wu, Y., Zhang, A. Q., and Yew, D. T. (2005). Age related changes of various markers of astrocytes in senescence-accelerated mice hippocampus. Neurochem. Int. 46, 565-574. doi: 10.1016/j.neuint.2005.01.002

Wyse, C. A., and Coogan, A. N. (2010). Impact of aging on diurnal expression patterns of CLOCK and BMAL1 in the mouse brain. Brain Res. 1337, 21-31. doi: 10.1016/j.brainres.2010.03.113

Xie, L., Poteet, E. C., Li, W., Scott, A. E., Liu, R., Wen, Y., et al. (2010). Modulation of polymorphonuclear neutrophil functions by astrocytes. J. Neuroinflammation 7:53. doi: 10.1186/1742-2094-7-53

Xu, J., Kobayashi, S., Yamaguchi, S., Iijima, K., Okada, K., and Yamashita, K. (2000). Gender effects on age-related changes in brain structure. AJNR Am. J. Neuroradiol. 21, 112-118.

Xuan, A., Long, D., Li, J., Ji, W., Hong, L., Zhang, M., et al. (2012). Neuroprotective effects of valproic acid following transient global ischemia in rats. Life Sci. 90, 463-468. doi: 10.1016/j.lfs.2012.01.001

Yoshida, T., Goldsmith, S. K., Morgan, T. E., Stone, D. J., and Finch, C. E. (1996). Transcription supports age-related increases of GFAP gene expression in the male rat brain. Neurosci. Lett. 215, 107-110. doi: 10.1016/s03043940(96)12966-9

Zamanian, J. L., Xu, L., Foo, L. C., Nouri, N., Zhou, L., Giffard, R. G., et al. (2012). Genomic analysis of reactive astrogliosis. J. Neurosci. 32, 6391-6410. doi: 10.1523/JNEUROSCI.6221-11.2012

Zhang, C. (2008). The role of inflammatory cytokines in endothelial dysfunction. Basic Res. Cardiol. 103, 398-406. doi: 10.1007/s00395-008-0733-0

Zhang, Y., Kim, M. S., Jia, B., Yan, J., Zuniga-Hertz, J. P., Han, C., et al. (2017). Hypothalamic stem cells control ageing speed partly through exosomal miRNAs. Nature 548, 52-57. doi: 10.1038/nature23282

Zhang, Y., Sloan, S. A., Clarke, L. E., Caneda, C., Plaza, C. A., Blumenthal, P. D., et al. (2016). Purification and characterization of progenitor and mature human 
astrocytes reveals transcriptional and functional differences with mouse. Neuron 89, 37-53. doi: 10.1016/j.neuron.2015.11.013

Zheng, W., Ren, S., and Graziano, J. H. (1998). Manganese inhibits mitochondrial aconitase: a mechanism of manganese neurotoxicity. Brain Res. 799, 334-342. doi: 10.1016/s0006-8993(98)00481-8

Zhu, X., Hill, R. A., Dietrich, D., Komitova, M., Suzuki, R., and Nishiyama, A. (2011). Age-dependent fate and lineage restriction of single NG2 cells. Development 138, 745-753. doi: 10.1242/dev.047951

Zlokovic, B. V. (2008). The blood-brain barrier in health and chronic neurodegenerative disorders. Neuron 57, 178-201. doi: 10.1016/j.neuron.2008. 01.003
Conflict of Interest Statement: The authors declare that the research was conducted in the absence of any commercial or financial relationships that could be construed as a potential conflict of interest.

Copyright (c) 2018 Palmer and Ousman. This is an open-access article distributed under the terms of the Creative Commons Attribution License (CC BY). The use, distribution or reproduction in other forums is permitted, provided the original author(s) and the copyright owner(s) are credited and that the original publication in this journal is cited, in accordance with accepted academic practice. No use, distribution or reproduction is permitted which does not comply with these terms. 